Bull. Mater. Sci., Vol. 17, No. 6, November 1994, pp. 733-745. (C) Printed in India.

\title{
Development of ultra light magnesium-lithium alloys
}

\author{
C R CHAKRAVORTY \\ Defeoce Metallurgical Research Laboratory, Kanchanbagh, Hyderabad 500 258, India
}

\begin{abstract}
Magnesium-lithium alloys are among the lowest density metallic materials. Addition of lithium, with a relative density of 0.53 , in magnesium reduces the density of the alloy significantly. Furthermore, addition of nearly $11 \mathrm{wt} . \%$ lithium converts hexagonal close packed structure of pure magnesium to a body centered cubic lattice, markedly improving formability of the alloy. The development of these alloys, however, had been hampered due to the high reactivity of lithium and magnesium in the molten state and also, due to poor creep resistance and instability of mechanical properties at room temperature. In an attempt to indigenize these ultra light alloys for possible applications in Indian satellite programme, detailed research work was initiated in DMRL. The difficulties associated with producing sound cast ingots have been overcome by controlling melting and casting parameters of these alloys. Extensive work has been done on structure-property correlation of alloys with varying lithium content and minor alloying additions. Based on these work, advanced magnesium-lithium alloys have been developed with improved tensile properties, room temperature stability and creep resistance. Wrought products (plates/sheets) of magnesium-lithium alloy have been supplied to ISAC, Bangalore and are being used in their INSAT-2 programme. This paper describes the systematic studies carried out in the laboratory to indigenize these ultra light alloys.
\end{abstract}

Keywords. Ultra light $\mathrm{Mg}-\mathrm{Li}$ alloy; flux cover melting; ingot casting; instability; mechanical properties; creep resistance; microstructure.

\section{Introduction}

Low density of magncsium $(1.74 \mathrm{~g} / \mathrm{cc})$ has led to its association with transportation and especially, with acrospace industry which has provided great stimulus to the development of magnesium-based alloys during last few decades. In the course of the past work, various alloying elements have been added to magnesium so as to produce alloys of high strength, high creep resistance and low density. The development of magnesium-lithium alloys began in the early 1930s. The object of this early work was the development of light weight magnesium-lithium alloys exhibiting higher strengths, better formability and less directionality of properties than conventional magnesium alloys. Lithium, with a relative density of 0.53 , is the lightest of all metals and has extensive solid solubility in magnesium (Nayeb-Hashemi et al 1984). Furthermore, addition of nearly 11 wt.\% lithium converts hexagonal close packed structure of pure magnesium to a body centered cubic lattice, markedly improving formability of the alloy (Munroe 1966).

In view of the aforementioned characteristics, a number of attempts have been made to develop $\mathrm{Mg}$-based alloys with lithium as major alloying additions. However, these attempts met with difficulties associated with melting and casting (Jackson et al 1949; Saia and Edelman 1962; Saia et al 1967; Saia and Edelman 1968; Beniere et al 1968), instability of mechanical properties at room temperature (Jones and Hogg 1957; Raynor 1959; McDonald 1968, 1969; Alamo and Banchik 1980; 
Kazakov et al 1983), poor corrosion resistance (Kalimullin and Kozhevnikov 1985; Kalimullin and Berdnikov 1986; Das and Fraser 1989) and excessive creep at relatively low stresses (Raynor 1959; Jackson and Frost 1967). Despite considerable effort in Europe and USA it appeared that the only practical possibilities were to produce strong magnesium-lithium alloys which were not stable or stable magnesium-lithium alloys which were not strong and subsequently this development work was abandoned (Frost 1965). Further, the incomplete understanding of the strengthening mechanism of this alloy system led to the failure of developing this alloy into a potential material for aerospace industries.

\subsection{Development efforts at DMRL}

In the recent past, the demand for magnesium-lithium alloy components has considerably increased for use in aerospace and allied fields where reduction in the intrinsic weight of the design is of paramount importance. Consequently, magnesium-lithium alloys have been investigated more intensively in the last decade mainly to overcome their limitations as potential materials for various structural applications. In the mid $80 \mathrm{~s}$, a research programme was initiated at the Defence Metallurgical Research Laboratory (DMRL), Hyderabad for the indigenous development of magnesium-lithium alloys via ingot metallurgy route in order to meet the requirements of the Indian space industry. It is the purpose of the present paper to describe the systematic studies carried out at various stages of continuing magnesium-lithium development programme in the laboratory. Current applications of these alloys, together with the recent developments on this alloy type are also discussed within the context of the present paper.

\section{Melting, casting and characterization}

In the present study, magnesium and lithium were used as pure metals, while aluminium and other alloying elements were added in the form of master alloys. These materials were added with the intention of investigating the viability of producing magnesium-lithium alloys from commercially available raw materials. It may be mentioned here that the past work on these alloys were mostly carried out using ultra pure materials. The impurity contents of raw materials and flux covers used in the present study are given in table 1 . Chemical compositions of different alloys prepared under halide flux covers using commercially available raw materials are given in table 2. Details of the melting, casting and fabrication techniques have been reported previously (Singh and Chakravorty 1988a, b; Singh et al 1989a). Briefly, $\mathrm{Mg}-\mathrm{Li}-\mathrm{Al}$ alloys were made by mixing molten magnesium and aluminiummagnesium master alloy in a mild steel crucible at around $1023 \mathrm{~K}$ and pouring over molten lithium, separately melted in a stainless steel crucible and kept at around $.573 \mathrm{~K}$. The melt was then chill-cast in a mild steel mould. For the alloy with zirconium, magnesium and magnesium-zirconium master alloy were heated to a temperature exceeding $1073 \mathrm{~K}$ and then molten aluminium-magnesium master alloy was added to this melt just before pouring over molten lithium. Here special care was taken to minimize the operation time after aluminium addition. This was necessary to retain zirconium in the alloy. At this time, the kinetics of aluminium- 
zirconium compound formation and also the extent of compound formation in the melt or subsequent to the casting is not clear. Nevertheless, chemical analysis indicated similar concentration of zirconium in various parts of the cast ingot. The cast ingots were rolled at $573 \mathrm{~K}$. Rolled plates/sheets were solution-treated at $573 \mathrm{~K}$ for $1 \mathrm{~h}$ followed by ageing at $453 \mathrm{~K}$ for $2 \mathrm{~h}$. Specimens for optical metallography were etched in $2 \%$ nital, whilst those for transmission electron microscopy were chemically polished in a solution containing $2 \%$ nitric acid in ethyl alcohol cooled below $283 \mathrm{~K}$ (Urakami et al 1970).

Tensile tests were performed in an INSTRON machine at various strain rates (from $4.4 \times 10^{-5}$ to $1.8 \times 10^{-3} \mathrm{sec}^{-1}$ ) and temperatures (298 to $473 \mathrm{~K}$ ). For elevated temperature tests, samples were soaked at testing temperature for 30 min. Tests were conducted in both longitudinal and transverse directions with respect to the rolling direction. For hot rolled plates, with thickness of more than $10 \mathrm{~mm}$, round tensile specimens with gauge diameter of $6.35 \mathrm{~mm}$ and gauge length of $19 \mathrm{~mm}$ were used, while for thinner plates/sheets, flat tensile samples of $19 \mathrm{~mm}$ gauge length, $5 \mathrm{~mm}$ width and thicknesses less than $4 \mathrm{~mm}$ were used. Creep tests were performed on constant load machines with a lever ratio of $1: 10$ and extensions were measured with two parallel LVDTs. The static elastic modulus was measured by non-destructive resonance technique. Densities were measured using the two-fluid method, with air and ethanol as fluids. Scanning and transmission electron microscopy was carried out on ISI 100A and Philips EM430T microscope respectively.

\section{Major achievements}

\subsection{Melting characteristics}

A comparison of alloy compositions given in table 2 with impurity contents present in the raw materials and flux covers (table 1) indicates minor pick up of iron, nickel and calcium by the alloys during melting. The analysis, however, indicates relatively lower levels of sodium and potassium in the alloy. Lower levels of $\mathrm{Na}$ and $K$ in the alloy are due to elimination of these alkali metals from the melt as vapours at holding temperatures (Singh 1994a). It has been observed that the presence of impurities other than sodium can be tolerated in the alloy to considerably higher levels (Jackson and Frost 1967). Therefore, minor pick up of iron, nickel and calcium observed during melting will not adversely affect the properties of alloy. These findings indicate that the melting process employing suitable flux covers and crucible materials appears to be a viable technology.

Table 1. Impurity contents (wt.\%) of saw materials used in preparing magnesium-lithium alloys.

\begin{tabular}{lccccccccc}
\hline Metal/flux & $\mathrm{Fe}$ & $\mathrm{Si}$ & $\mathrm{Na}$ & $\mathrm{K}$ & $\mathrm{Ca}$ & $\mathrm{Ni}$ & $\mathrm{Mn}$ & $\mathrm{SO}_{4}$ & Purity \\
\hline Magnesium & 0.008 & $<0.01$ & - & - & - & 0.003 & 0.003 & - & 99.8 \\
Aluminium & 0.07 & 0.06 & 0.001 & - & - & - & - & - & 99.8 \\
Lithium & 0.015 & - & 0.005 & 0.004 & 0.006 & - & - & - & 99.8 \\
LiCl & 0.001 & - & 0.006 & 0.01 & 0.01 & - & - & 0.01 & 99.0 \\
LiF & 0.004 & 0.01 & - & - & - & - & - & 0.02 & 99.0 \\
\hline
\end{tabular}


Non-reactivity of molten lithium with $304 \mathrm{~L}$ stainless steel up to $873 \mathrm{~K}$ (Averill et al 1981) and very low solid solubility of iron in the molten magnesium (Polmear 1989) avoids possibility of metal-crucible reaction during melting. However, prior to pouring, alloys were held in $304 \mathrm{~L}$ stainless steel crucible at temperatures well above $950 \mathrm{~K}$. At this temperature, iron and nickel pick up in the alloy were observed due to corrosive attack of molten metal on crucible material. The dissolution of nickel in molten magnesium is a well observed phenomenon (Brace and Allen 1957). The dissolution of iron in the alloy, on the other hand, is not well understood. Considering low solubility of iron in magnesium in the present working temperature range, it may be stated that the corrosive attack of lithium controls the iron pick up in the alloy during holding period. Lithium, which does not attack 304L stainless steel up to $873 \mathrm{~K}$ (Averill et al 1981), perhaps becomes corrosive at higher temperatures. It has been reported that delay time prior to grain boundary penetration in 304L stainless steel by liquid lithium had a temperature dependence (Patterson et al 1975). The complexity of liquid lithium corrosion is also related to various other factors, such as thermal and chemical potential gradients, variations of elemental solubility as a function of temperature, role of interstitial contaminants in liquid lithium etc. The actual mechanism of attack on 304L stainless steel by magnesium-lithium alloy melt for iron pick up, however, needs further investigation.

To study the suitability of flux covers, the feasibility of various direct displacement reactions between molten metal and compounds present in the flux cover were worked out. Possible reactions of lithium with $\mathrm{MgCl}_{2}$ and $\mathrm{CaF}_{2}$, present in magnesium flux, indicates reasonably higher limiting activity of reaction products (Singh 1994a). Thus use of magnesium flux cover over molten magnesium-lithium alloy will result in lithium loss as well as calcium pick up by the alloy $(\mathrm{LiCl}+\mathrm{LiF})$ flux, on the other hand, remains inert to the alloy system. Therefore, it can be safely used as flux cover for the alloy during holding period. However, minor pick up of calcium is observed in the alloy even when $\mathrm{LiCl}-\mathrm{LiF}$ flux cover is used during holding period (table 2). This can be attributed to relatively higher level of calcium present as impurity in lithium chloride (table 1). Also, the inability of $\mathrm{LiCl}-\mathrm{LiF}$ flux to cover molten magnesium-lithium alloy effectively results in loss of lithium as dross during holding period. Therefore, to minimize the loss of lithium during holding period, sulphur powder was sprinkled over the molten alloy which creates neutral atmosphere and minimizes atmospheric oxidation of the alloy to a large extent.

Table 2. Chemical compositions (wt.\%) of different batches of magnesium-lithium alloys.

\begin{tabular}{|c|c|c|c|c|c|c|c|c|c|c|}
\hline \multirow{2}{*}{$\begin{array}{l}\text { Charge } \\
\text { composition (wt.\%) }\end{array}$} & \multirow{2}{*}{$\begin{array}{c}\text { Melt size } \\
(\mathbf{k g})\end{array}$} & \multirow[b]{2}{*}{$\mathbf{L i}$} & \multirow[b]{2}{*}{ Al } & \multicolumn{5}{|c|}{ Composition (wt.\%) of the alloy } & \multirow[b]{2}{*}{$\mathbf{K}$} & \multirow[b]{2}{*}{$\mathrm{Ca}$} \\
\hline & & & & $\mathbf{Z r}$ & $\mathbf{F e}$ & $\mathbf{S i}$ & $\mathbf{N i}$ & $\mathbf{N a}$ & & \\
\hline \multirow[t]{6}{*}{$\mathrm{Mg}-12 \mathrm{Li}-1.5 \mathrm{Al}$} & 2 & 10.8 & 1.56 & - & 0.013 & $<0.01$ & 0.005 & $<0.002$ & $<0.002$ & 0.008 \\
\hline & 10 & $11 \cdot 2$ & 1.54 & - & 0.013 & $<0.01$ & 0.005 & $<0.002$ & $<0.002$ & 0.006 \\
\hline & 20 & 11.4 & 1.52 & - & 0013 & $<0.01$ & 0.004 & $<0.002$ & $<0.002$ & 0.006 \\
\hline & 30 & 11.5 & 1.52 & $=$ & 0.013 & $<0.01$ & 0.004 & $<0.002$ & $<0.002$ & 0.005 \\
\hline & 40 & 11.6 & 1.51 & - & 0.010 & $<0.01$ & 0.003 & $<0.002$ & $<0.002$ & 0.003 \\
\hline & 50 & 11.6 & 1.50 & - & 0.010 & $<0.01$ & 0.003 & $<0.002$ & $<0.002$ & 0.003 \\
\hline Mg-15Li-1.5Al & 10 & 13.8 & 1.55 & - & 0.014 & $<0.01$ & 0.005 & $<0.002$ & $<0.002$ & 0.007 \\
\hline Mg-9Li-1.5Al & 10 & 8.4 & 1.53 & - & 0.013 & $<0.01$ & 0.005 & $<0.002$ & $<0.002$ & 0.006 \\
\hline $\mathrm{Mg}-4 \mathrm{Li}-1.5 \mathrm{Al}$ & 10 & 3.8 & 1.52 & - & 0.011 & $<0.01$ & 0.005 & $<0.002$ & $<0.002$ & 0.005 \\
\hline $\mathrm{Mg}-12 \mathrm{Li}-1.5 \mathrm{Al}-0.6 \mathrm{Zr}$ & 10 & 11.4 & 1.57 & 0.14 & 0.013 & $<0.01$ & 0.005 & $<0.002$ & $<0.002$ & 0.006 \\
\hline
\end{tabular}


These observations point out the difficulties encountered in melting of magnesiumlithium alloys under halide flux cover. To aveid these problems, the alloy prepared under a flux cover must not be held in crucibles prior to pouring for unnecessarily long period not only to avoid loss of costly lithium but also to keep the iron, nickel and calcium contents of the alloy sufficiently low for better properties. Perhaps this technology car be improved further by replacing 304L stainless steel with suitable ceramic material as crucible material. However, for all other parts of the present work, magnesium-lithium alloys were prepared using 304L stainless steel and restricting the holding time to bare minimum $(<5 \mathrm{~min})$.

\subsection{Mechanical behaviour}

Magnesium-lithium alloys can be classified into three major categories based on the constitutional phases present in the system (figure 1). They are; $\alpha$ alloys with lithium less than $5 \mathrm{wt} . \%, \beta$ alloys with lithium more than $11 \mathrm{wt} \%$ and $(\alpha+\beta)$ alloys with lithium ranging from 5 to 11 wt.\%. Different proportions of $\alpha$ and $\beta$ in the alloy significantly changes the mechanical behaviour of this system. $\mathrm{Mg}-\mathrm{Li}-\mathrm{Al}$ alloys corresponding to each of these categories have been studied. Typical microstructures of $\alpha,(\alpha+\beta)$ and $\beta$ alloys are shown in figure 2. A

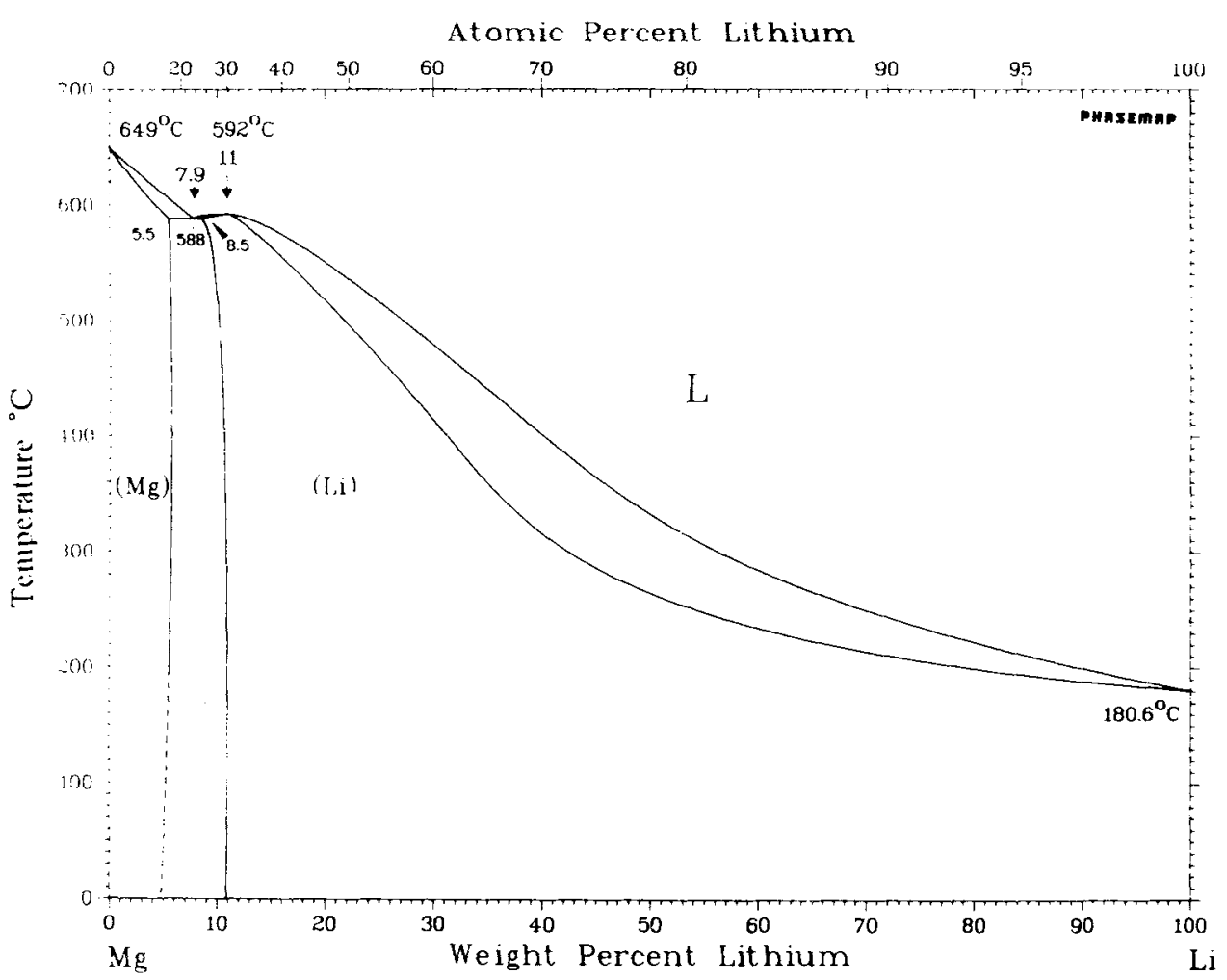

Figure 1. Equilibrium phase diagram of binary magnesium-lithium system. 


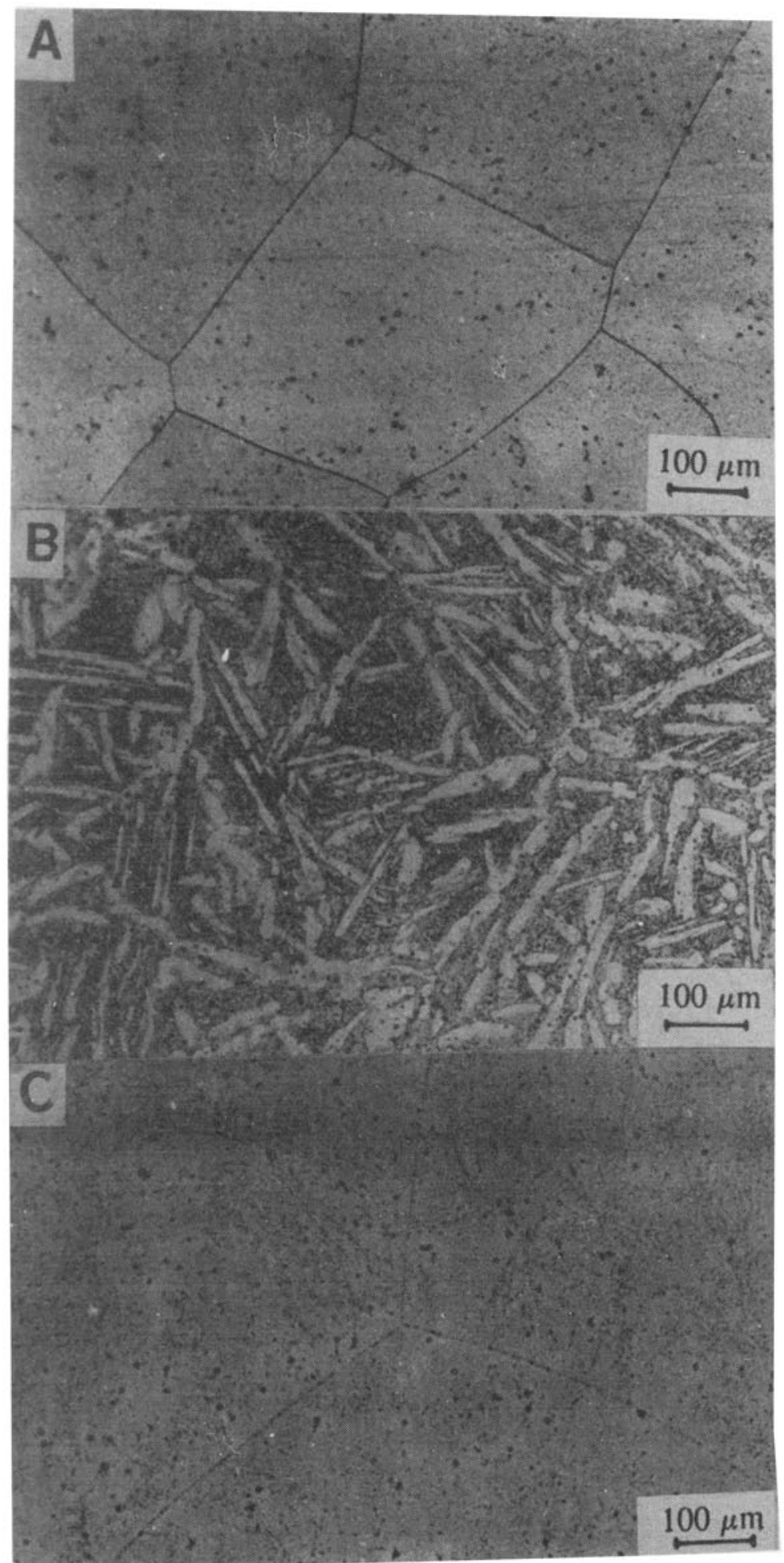

Figure 2. Typical microstructures of (A) $\alpha$, (B) $\alpha+\beta$ and (C) $\beta$ alloys. 
comparison of different alloys based on ternary $\mathrm{Mg}-\mathrm{Li}-\mathrm{Al}$ system indicated that optimum balance of ductility, strength and stability is achieved in the alloy with around 11 wt.\% lithium (Singh 1994a). $\mathrm{Mg}-11 \mathrm{Li}-1.5 \mathrm{Al}$ alloy was, therefore, selected as the base alloy for further studies.

3.2a Instability of mechanical properties: The instability of mechanical properties associated magnesium-lithium alloys has been reported by several workers (Jones and Hogg 1957; McDonald 1968; Singh and Chakravorty 1988a, c). Instability in these alloys is associated with very high atomic mobility of lithium, even at relatively low temperatures (Iwadate et al 1987). Exceptionally high vacancy concentration and the lithium atom jump frequency result, not only in great mobility for both vacancies and lithium atoms, but also in rapid transport of other solute species. This leads to rapid coarsening of precipitates in combination with rapid dislocation climb, which destroys the efficiency of conventional hardening mechanism.

Magnesium-lithium alloys with different minor additions $(\mathrm{Zr}, \mathrm{Mn}, \mathrm{Ce}, \mathrm{Be}, \mathrm{Y}$, $\mathrm{Th}$ and $\mathrm{Nd}$ ) were cast, processed and heat treated under identical conditions to compare the effect of these elements on stability of mechanical properties of the alloy at room temperature. Tensile properties of all the alloys were evaluated in both rolled and stabilized conditions and are listed in table 3 . It can be seen from this table that all the alloys studied show degradation in strength as a result of stabilization treatment. In $\mathrm{Mg}-\mathrm{Li}-\mathrm{Al}-\mathrm{Zr}$ alloy, however, only a minor drop of around $6 \%$ in strength was observed after stabilization. The instability associated with this alloy, therefore, can be regarded as insignificant. Further, zirconium appears to be the most beneficial addition in improving the specific strength of the alloy at room temperature (Singh et al 1989b; Singh and Mishra 1990) as well as at elevated temperatures (Singh 1994a). This gives an indication that the $\mathrm{Al}_{3} \mathrm{Zr}$ precipitates which have formed as a result of zirconium addition are much more stable than the precipitates normally present in the ternary $\mathrm{Mg}-\mathrm{Li}-\mathrm{Al}$ system. This is to be expected, since zirconium has lower diffusivity (Vesey and Bray 1963-64) and limited solid solubility (Emley and Duncumb 1961-62) in magnesium-the factors which govern particle coarsening kinetics (Wagner 1961). Limited transmission electron microscopy showed fine $\mathrm{Al}_{3} \mathrm{Zr}$ precipitates at grain boundaries and also within the grains in $\mathrm{Mg}-\mathrm{Li}-\mathrm{Al}-\mathrm{Zr}$ alloy (figure 3 ).

Table 3. Drop in strength as a result of stabilization treatment in magnesium-lithium alloys.

\begin{tabular}{|c|c|c|c|c|c|c|c|c|}
\hline \multirow[b]{3}{*}{ Alloy } & \multirow[b]{3}{*}{$\begin{array}{c}\text { Density } \\
(\mathrm{g} / \mathrm{cc})\end{array}$} & \multicolumn{6}{|c|}{ Tensile properties } & \multirow{3}{*}{$\begin{array}{l}\text { Drop in } \\
\text { strength } \\
\quad(\%)\end{array}$} \\
\hline & & \multicolumn{3}{|c|}{ As rolled } & \multicolumn{3}{|c|}{ Stabilized } & \\
\hline & & $\begin{array}{c}0.2 \% \text { PS } \\
(\mathrm{MPa})\end{array}$ & $\begin{array}{c}\text { UTS } \\
(\mathrm{MPa})\end{array}$ & $\begin{array}{c}\text { Elong. } \\
(\%)\end{array}$ & $\begin{array}{c}0.2 \% \mathrm{PS} \\
(\mathrm{MPa})\end{array}$ & $\begin{array}{l}\text { UTS } \\
(\mathrm{MPa})\end{array}$ & $\begin{array}{c}\text { Elong. } \\
(\%)\end{array}$ & \\
\hline $\mathrm{Mg}-11 \mathrm{Li}-1 \cdot 5 \mathrm{Al}$ & 1.41 & 145 & 174 & 39 & 113 & 130 & 50 & 25 \\
\hline $\mathrm{Mg}-11 \mathrm{Li}-1 \cdot 5 \mathrm{Al}-0 \cdot 14 \mathrm{Zr}$ & 1.45 & 170 & 220 & 25 & 140 & 207 & 17 & 6 \\
\hline $\mathrm{Mg}-11 \mathrm{Li}-1 \cdot 5 \mathrm{Al}-0.35 \mathrm{Mn}$ & 1.52 & 150 & 200 & 30 & 130 & 170 & 20 & 15 \\
\hline $1 \mathrm{Mg}-11 \mathrm{Li}-1 \cdot 5 \mathrm{Al}-1.0 \mathrm{Ce}$ & 1.60 & 150 & 205 & 25 & 120 & 170 & 12 & 17 \\
\hline $\mathrm{Mg}-11 \mathrm{Li}-1.5 \mathrm{Al}-0.013 \mathrm{Be}$ & $\mathrm{I} \cdot 41$ & 165 & 180 & 35 & 110 & 135 & 40 & 25 \\
\hline $\mathrm{Mg}-11 \mathrm{Li}-1.5 \mathrm{Al}-0.2 \mathrm{Y}$ & $\mathrm{i} .47$ & 150 & 185 & 30 & 115 & 160 & 25 & 14 \\
\hline $\mathrm{Mg}-11 \mathrm{Li}-1 \cdot 5 \mathrm{Al}-0 \cdot 1 \mathrm{Th}$ & 1.50 & 160 & 185 & 25 & 120 & 160 & 30 & 14 \\
\hline $\mathrm{Mg}-11 \mathrm{Li}-1.5 \mathrm{Al}-0.47 \mathrm{Nd}$ & 1.55 & 180 & 200 & 12 & 135 & 160 & 20 & 20 \\
\hline
\end{tabular}




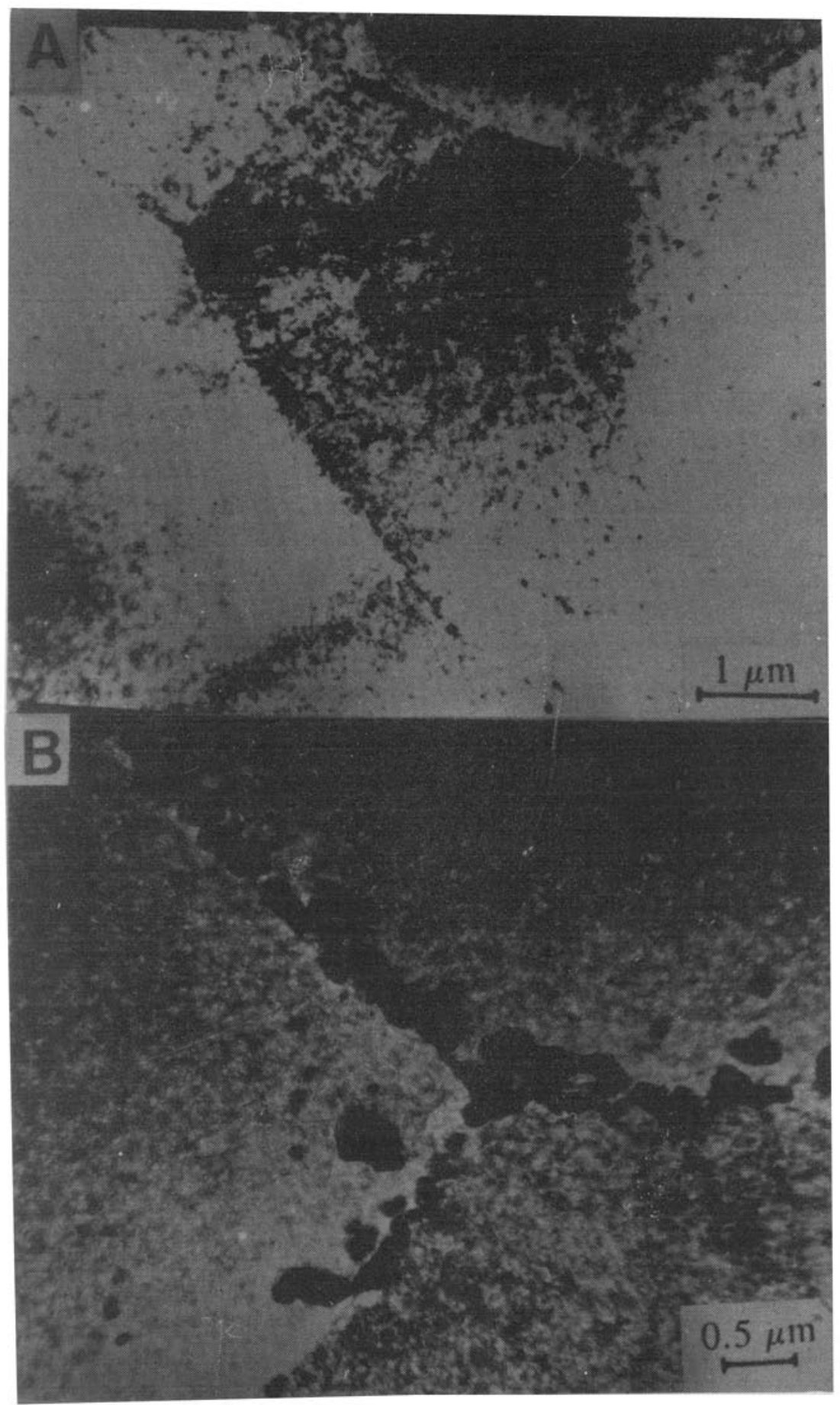

Figure 3. TEM micrographs of (A) $\mathrm{Mg}-\mathrm{Li}-\mathrm{Al}$ and (B) $\mathrm{Mg}-\mathrm{Li}-\mathrm{Al}-\mathrm{Zr}$ alloys. 
3.2b Ductility trough at elevated temperatures: Studies on temperature dependence of ductility in these alloys were also carried out. The tensile ductility of the $\mathrm{Mg}-\mathrm{Li}-\mathrm{Al}$ and $\mathrm{Mg}-\mathrm{Li}-\mathrm{Al}-\mathrm{Zr}$ alloys at various temperatures in the range 233-473 $\mathrm{K}$ is shown in figure 4 . It may be seen that the ductility of the $\mathrm{Mg}-\mathrm{Li}-\mathrm{Al}$ alloy drops significantly in the range $373-423 \mathrm{~K}$. The ductility trend observed has been correlated with fractography (Singh 1994a). It is observed that below $373 \mathrm{~K}$, these alloys are ductile with associated transgranular path (figure 5a). However, at higher temperatures $(373-423 \mathrm{~K})$, ductility decreases and a transition from transgranular to intergranular fracture is observed (figure 5b). This transition appears to be a result of localized diffusion of sodium and other alkali metals toward grain boundaries at elevated temperatures (Gur'ev et al 1980). Above $423 \mathrm{~K}$, however, there is again a sharp recovery in tensile ductility due to dynamic recrystallization, which results in desegregation of alkali metals at grain boundaries (Singh 1994a). Also, dynamic recrystallization results in accommodation of stress concentration formed at prior grain boundaries. In presence of zirconium a significant change in this behaviour is observed. Zirconium, which improves tensile strength of the alloy by fine precipitation of $\mathrm{Al}_{3} \mathrm{Zr}$, has also been found to promote early recrystallization in the material (Singh 1994a, b). Thus the ductility trough, which is postulated to be accomplished by the competition of the two diffusion controlled processes i.e. the grain boundary cavitation and dynamic recrystallization, is minimized to a large extent in presence of zirconium.

3.2c Improvement in creep resistance: Figure 6 shows variation of steady state creep rate of $\mathrm{Mg}-\mathrm{Li}-\mathrm{Al}$ and $\mathrm{Mg}-\mathrm{Li}-\mathrm{Al}-\mathrm{Zr}$ alloy with applied stress at room temperature. A comparison of the steady state creep rate data of these alloys clearly indicates remarkable improvement in creep resistance of the alloy after zirconium addition. It is important to note that $\mathrm{Mg}-\mathrm{Li}-\mathrm{Al}$ alloy creeps at a stress of $67 \mathrm{MPa}$, which is much below its yield strength of $113 \mathrm{MPa}$. On the other hand, the modified

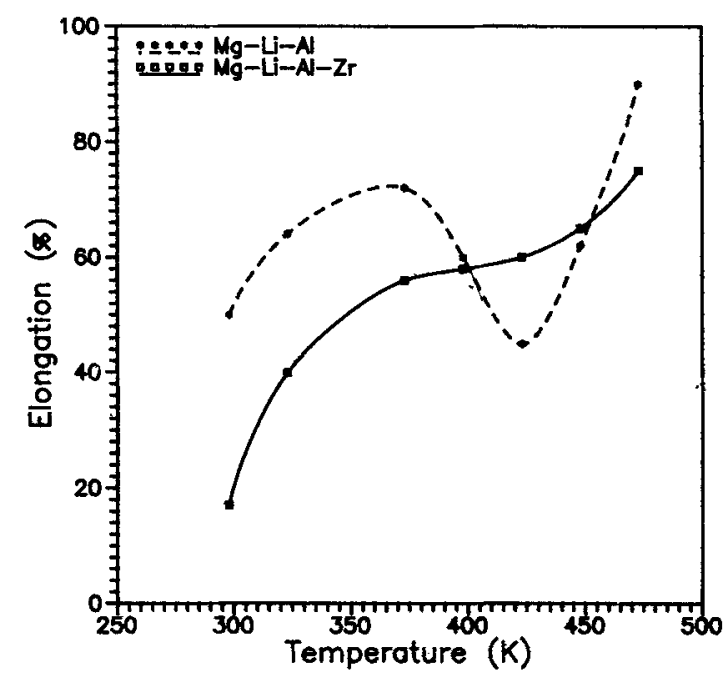

Figure 4. Effect of zirconium on high temperature ductility of magnesium-lithium alloy. 


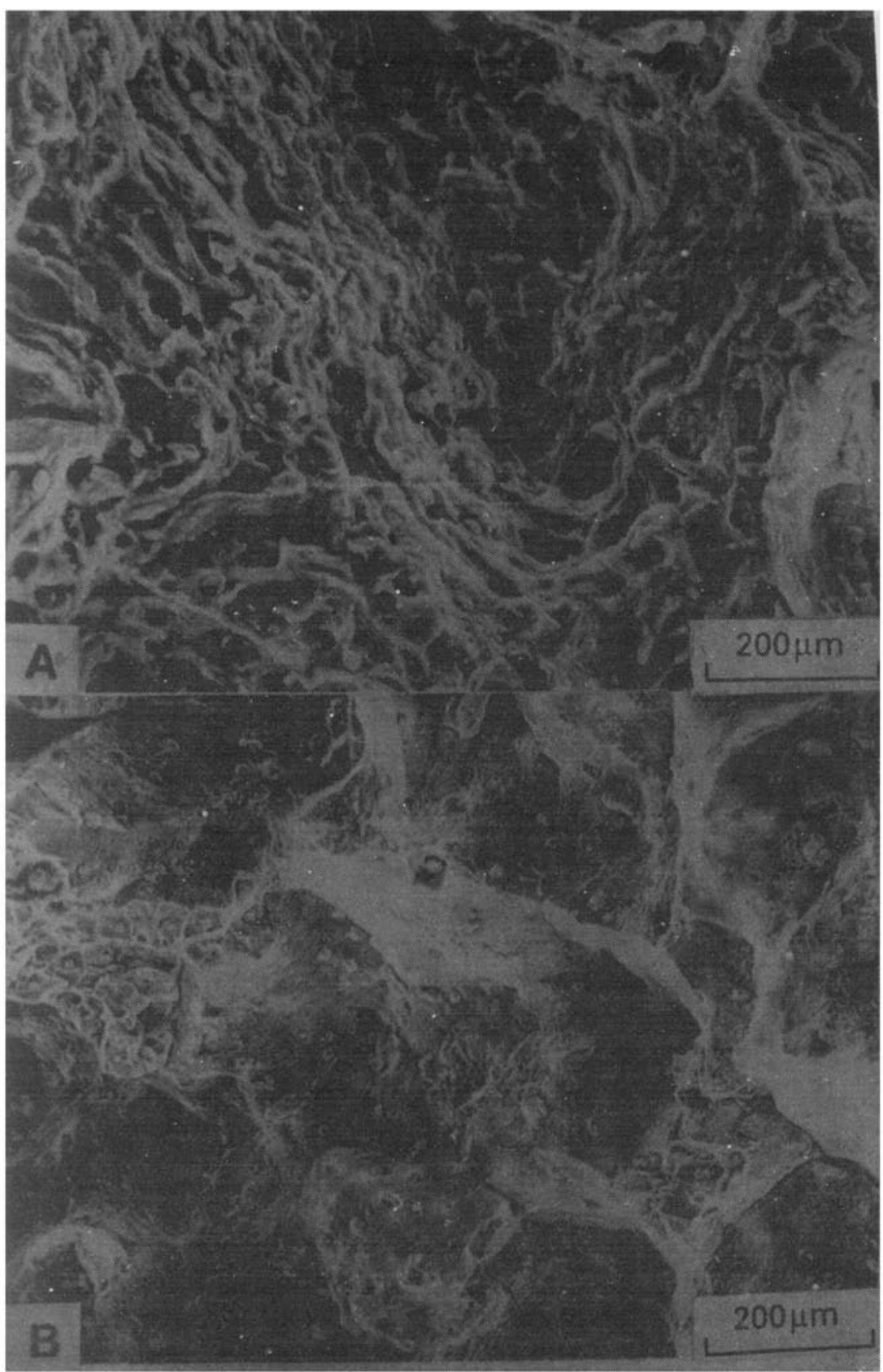

Figure 5. Scanning elcciron factographs showing (A) 1ransgranular and (B) intergranular fracture in $\mathrm{Mg}-11 \mathrm{Li}-1.5 \mathrm{Al}$ alioy.

$\mathrm{Mg}-\mathrm{Li}-\mathrm{Al}-\mathrm{Zr}$ alloy does not creep at any measurable rate up to $130 \mathrm{MPa}$. This value is far closer to the yield strength (140 MPa) of this alloy at room temperature. The observed improvement has been correlated with delayed power law breakdown in the alloy containing zirconium (Singh 1994a). 


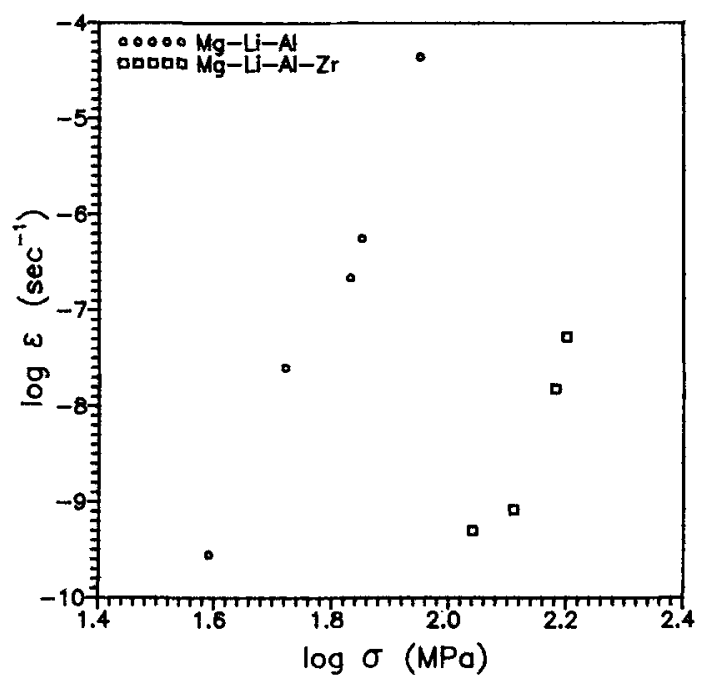

Iigure 6. Variation of steady state creep rate with stress at room temperature.

3.2d Protective coatings: Magnesium-lithium alloys are well known for their poor corrosion resistance. The poor oxidation/corrosion resistance of magnesium-lithium alloys is related to their high chemical reactivity and to the segregation of alloying elements leading to localized cathodic centres. Initial oxidation rates are relatively low due to the formation of protective hydroxide film on the surface. After sometime, however, this protective film breaks down giving rise to higher rate of oxidation. Electrodeposition on these alloys are difficult due to their high reactivity in aqueous solutions. Extensive development work carried out at ISAC, Bangalore has culminated in the development of thermally stable coating (Sharma 1988). These coatings have been used successfully on magnesium-lithium alloy components by ISAC, Bangalore for use in INSAT-2.

\section{Work in progress and future plans}

As discussed above, minor additions of zirconium improves the tensile strength and creep resistance of $\mathrm{Mg}-\mathrm{Li}-\mathrm{Al}$ alloy significantly. In an attempt to further improve both the strength and the modulus of the alloy, work has been initiated to develop magnesium-lithium matrix composites. It has been reported that ceramic fibres/ particles undergo significant degradation when kept in contact with molten lithium for a considerably longer duration (Mason et al 1989). Any reaction between reinforcement and matrix would lead to damage of the particles and formation of reaction products at the interface. This would prevent full realization of the strengthening potential of the composites. To avoid this, these composites are being made using solid state diffusion bonding technique (Singh et al 1993, 1994). Preliminary results indicate significant improvement in strength and modulus of the alloy with marginal drop in ductility.

Also, work is in progress to develop magnesium-lithium alloy with density of less than $1 \mathrm{~g} / \mathrm{cc}$. An alloy containing $50 \mathrm{wt} . \%$ lithium and $5 \mathrm{wt} . \%$ aluminium has 


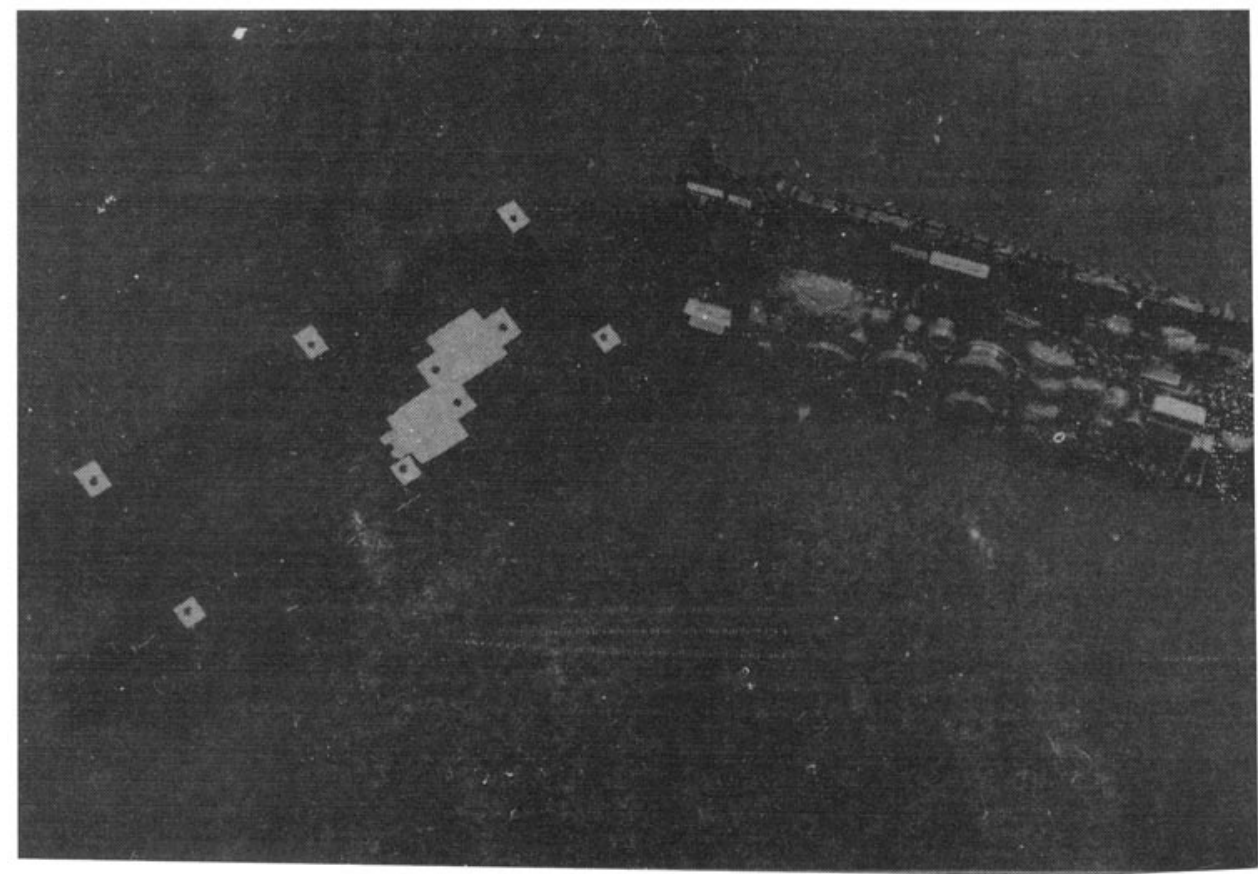

Figure 7. Magnesium-lithum alloy package box for INSAT-2

been cast and processed to $2 \mathrm{~mm}$ thick sheets. At present, characterization of this alloy is being persuaded.

\section{Summary}

Sound cast ingots of magnesium-lithium alloys have been produced by optimizing melting and casting parameters of these alloys. Wrought products of varying thickness $(0.5-60 \mathrm{~mm})$ have been made and supplied to ISAC, Bangalore. Close association of Indian Satellite Application Centre, Bangalore during the development phase has helped in development of products with requisite properties sought and have found extensive application in INSAT-2 series. Figure 7 shows a typical component fabricated from magnesium-lithium alloy for INSAT-2.

Major limitations of the alloy i.e. instability of mechanical properties at room temperature and poor creep resistance have been overcome to a large extent by minor additions of zirconium. Magnesium-lithium composites having improved strength and modulus are being developed. The new improved alloy/composite shows potential for large scale exploitation as structural material in aerospace and allied industries. Interest shown by $\mathrm{M} / \mathrm{s}$ Lockheed Company, USA for obtaining magnesium-lithium alloy sheets from DMRL also shows the export potential for this material.

\section{Acknowledgements}

The author is grateful to Dr P Rama Rao, Secretary, DST and former Director, DMRL for the initiation of the magnesium-lithium alloy development programme at DMRL and for providing constant encouragement and support for the programme. 
Shri S L N Acharyulu, Director, DMRL is gratefully acknowledged for encouragement. The contribution of most of the groups of DMRL specially Light Alloy Foundry Group are gratefully acknowledged for making the magnesium-lithium alloy development programme a success.

\section{References}

Alamo A and Banchik A D 1980 J. Mater. Sci. 15222

Averill W A, Olsen D L, Matlock D K and Edwards G R 1981 Proc. of the first int. conf. on Al-Li alloys (eds) T H Sanders Jr and E A Starke Jr (Warrendale, Pa: TMS-AIME) p. 9

Beniere F, Chemla M, Aucouturier M, La Combe P and Roques-Carmes C 1968 Corrosion 2483

Brace A W and Allen F A 1957 Magnesium casting technology (London: Chapman and Hall)

Das S and Fraser H L 1989 Proc. of light weight alloys for aerospace applications (eds) E W Lee, E H Chia and N J Kim (Warrendale, Pa: TMS) p. 151

Emley E F and Duncumb P 1961-62 J. Inst. Met. 90360

Frost P D 1965 NASA-SP-5028 (Washington DC: NASA)

Gur'ev I I, Elkin F M and Kudryashov V G 1980 Structure and properties of light alloys (ed.) A M Korol'kov (New'Delhi: Amerind Publishing Co.) p. 190

Iwadate Y, Lassouari M, Lantelme F and Chemla M $1987 \mathrm{~J}$. Appl. Electrochem. 17385

Jackson J H, Frost P D, Loonam A C, Eastwood L W and Long C H 1949 Trans. AIME 185149

Jackson R J and Frost P D 1967 NASA-SP-5068 (Washington DC: Office of Technology Utilization Division, NASA)

Jones W R D and Hogg G V 1957 J. Inst. Met. 85255

Kalimullin R Kh and Kozhevnikov Yu Ya 1985 Met. Sci. Heat Treat. (USSR) 27272

Kalimullin R Kh and Berdnikov A T 1986 Prot. Met. (USSR) 22223

Kazakov A A, Timonova M A and Borisova L G 1983 Met. Sci. Heat Treat. (USSR) 25682

Mason J F, Warwick C M, Smith P J, Charles J A and Clyne T W 1989 J. Mater. Sci. 243934

McDonald J C 1968 Trans. ASM 61505

McDonald J C 1969 J. Inst. Met. 97353

Munroe R A 1966 Metal Progress 9089

Nayeb-Hashemi A A, Clark J B and Pelton A D 1984 Bull. Alloy Phase Diagrams 5365

Patterson R A, Schlager R J and Olson D L 1975 J. Nucl. Mater. 57312

Polmear I J 1989 Light alloys-Metallurgy of the light metals (New York: Chapman and Hall, Inc.)

Raynor G V 1959 The physical metallurgy of magnesium and its alloys (London: Pergamon Press)

Saia A and Edelman R E 1962 Foundry 9038

Saia A and Edelman R E 1968 Modern Casting 53165

Saia A, Edelman R E and Gilmore H L 1967 Modern Casting 52105

Sharma A K 1988 Met. Finish 8633

Singh R K 1994a Preparation and characterization of magnesium-lithium alloys, Ph D Thesis, Banaras Hindu University, Varanasi

Singh R K 1994b J. Mater. Sci. Lett. 13744

Singh R K and Chakravorty C R 1988a Trans. IIM 41153

Singh R K and Chakravorty C R 1988b Proceedings of the aerospace structures-Advances and future trends (Trivandrum: Aeronautical Society of India)

Singh R K and Chakravorty C R 1988c DMRL Technical Report DMRL-TR-8876

Singh R K and Mishra R S 1990 Scr. Metall. 24451

Singh R K, Sudhakar B and Chakravorty C R 1989a Indian Foundry J. 3521

Singh R K, Mishra R S and Chakravorty C R 1989b DMRL Technical Report DMRL-TR-89 102

Singh R K, Mukhopadhyaya A K, Sudhakar B, Bhanu Prasad V V, Mahajan Y R and Chakravorty C R 1993 Adv. Comp. News Letter 23

Singh R K, Sudhakar B and Chakravorty C R 1994 Proceedings of Al-Li and Mg-Li alloys-Science, technology and application (Bangalore: HAL)

Urakami A, Meshii M and Fine M E 1970 Acta Metall. 1887

Vesey I M and Bray H J 1963-64 J. Inst. Met. 92383

Wagner C. 1961 Z. Electrochemie 65581 